\title{
Expanding Inequality:
}

\section{Trends in Educational Stratification during China's Market Transition}

\author{
Rob J. Gruijters ${ }^{1}$
}

\begin{abstract}
This study looks at educational inequality in China, a country that has greatly expanded access to education in recent decades. It uses a sequential logit model to study the changing impact of family background on educational transitions and educational attainment, comparing birth cohorts that completed their schooling during different stages of the market transition process. Data are derived from the China Family Panel Studies (CFPS), a large and nationally representative household survey that provides detailed retrospective information. The findings show that in reform-era China educational inequality has increased despite large-scale educational expansion. Since the onset of the market reforms the importance of social origin has continuously increased, particularly at the crucial transition to senior high school. I suggest that the resulting pattern of expanding inequality can be explained by a combination of market-based educational reforms, increasing returns to education and massive increases in wider social and economic inequality.
\end{abstract}

Key words: China, China Family Panel Studies (CFPS), Educational expansion, Inequality of Educational Opportunity, Market reforms, Economic transition

\footnotetext{
${ }^{1}$ REAL Centre, Faculty of Education, University of Cambridge. rig85@cam.ac.uk
} 


\section{INTRODUCTION}

How economic modernization affects educational inequality is a contentious issue in sociological research. The Western experience has shown that inequality of educational opportunity (IEO) can be persistent even as overall educational attainment increases (Ishida, Müller, and Ridge 1995; Shavit and Blossfeld 1993), although more recent studies have found a slight reduction in class-based inequalities across cohorts (e.g. Breen et al. 2009), as well as considerable between-country variation (Van de Werfhorst and Mijs 2010). A number of researchers have sought to extend this framework to (post-)transitional societies, such as Russia (Gerber 2000; Gerber and Hout 1995) and various Latin American countries (Torche 2005, 2010). Transition societies experience widespread social upheaval and restructuring, as the old political and economic order is replaced by the new. China is an exemplary case in this regard, as its 'Great Transformation' is unparalleled in terms of magnitude, speed and geopolitical significance.

This study describes trends in educational inequality during China's Reform Era (1978-present), focusing in particular on the changing role of parents' education, household registration (rural or urban) and political capital. I limit myself to the reform period because I am interested in the most recent developments, and because variations in educational opportunities under state socialism (1949-1977) have been well documented elsewhere (Deng and Treiman 1997; Zhou, Moen, and Tuma 1998).

China is a particularly interesting case to study historical trends in IEO, for a number of reasons. Following the 1978 reforms, it moved from a highly egalitarian state socialist system to a market economy. Contrary to most other transitional societies, China's market transition took place in a context of relative political stability and was accompanied by an unprecedented economic boom, which increased both educational demand and returns to education. In the new market economy, educational success has become synonymous with economic advancement and social prestige. A fierce competition over access to more prestigious schools and universities emerged, and even the most disadvantaged parents generally have high hopes for their children's educational careers (Liu and Xie 
2015). In spite of skyrocketing socio-economic and geographic inequality, educational advancement continues to be seen as a relatively meritocratic process in China. This is partially the result of the nationwide system of high school and college entrance examinations, which was (re)instated following the market transition. The Confucian ideal of meritocracy and the promise of social mobility are important elements of the Communist Party's "socialist market economy", and help to explain why the Chinese population continues to accept increasing levels of distributive injustice (Whyte and Im 2014).

The study extends the literature on educational inequality in China in a number of ways. First, it compares cohorts that completed their schooling during different stages of the market transition process, including the most recent graduates, and addresses all relevant transitions within an integrated framework. It thereby provides a more comprehensive picture of trends in IEO than previous studies, which generally focus on specific transitions and time periods (e.g. Loyalka et al. 2017; Wu 2010; Yeung 2013) or on aggregate outcomes such as years of education (Golley and Kong 2016; Knight, John, Terry Sicular 2013). Second, it uses a combination of metrics (relative, absolute and cumulative) to present trends in IEO, in order to address some of the shortcomings of the classic educational transition model (Mare 1980). Finally, it uses a new and nationally representative dataset, which contains highly detailed measures of respondents' social origin.

The following sections introduce the main theoretical perspectives and provide some background on the Chinese education system, followed by the analytical strategy and empirical results. Finally, I discuss how my findings compare to those observed in other societies and identify potential explanations for the observed pattern of expanding inequality.

\section{ECONOMIC MODERNIZATION AND EDUCATIONAL MOBILITY: THEORETICAL PESPECTIVES}

Inequality of educational opportunity (IEO) can be defined as the extent to which educational attainment is dependent on ascribed characteristics such as gender, place of birth and social origin (Coleman 1967). A number of mechanisms have been identified that link social origin, particularly 
parents' education level and occupational status, to their children's educational outcomes. These include, among others, early childhood socialization, parents' ability to help with schoolwork, ability to pay for better schools, and differential expectations and evaluations of educational options. The combination of these mechanisms generally leads to robust relationships between social origins and educational outcomes, although the strength of the relationship strongly depends on the institutional context (see Breen and Jonsson 2005; Van de Werfhorst and Mijs 2010).

A related field of study seeks to explain how the effect of social origin varies over time, particularly during periods of economic modernization and educational expansion (e.g. Ballarino et al. 2009; Breen et al. 2009; Schindler and Lörz 2012; Shavit and Blossfeld 1993). By definition, educational expansion increases educational opportunities, in the sense that more people are able to obtain educational degrees. Whether expansion also facilitates equality of opportunity, so that educational attainment becomes less dependent on family background, remains an empirical question.

Modernization theory predicts that educational opportunities in industrializing societies will become increasingly inclusive and merit-based, rather than determined by family background. Economic development increases the demand for skilled workers, and reduces the pressure on children from poor families to leave school at an early age in order to work (Treiman 1970). It is therefore assumed that modernizing societies will move towards a system of mass education, in which selection into higher levels is based on objective criteria rather than family influence. Whereas modernization theory emphasizes sorting on (innate) ability in education, reproduction theory has focused on the ways in which educational institutions reward class-specific knowledge and attributes (e.g. Bourdieu and Passeron 1970). It suggests that in economically advanced societies, where traditional markers of social status have lost some of their value, elites will use the education system to reproduce and legitimize their advantaged position.

At least in OECD countries, evidence for these broad theoretical perspectives is mixed. Modernization theory was challenged by Shavit \& Blossfeld's Persistent Inequality (1993), which suggested that class 
differences in the odds of attaining higher levels of education remained stable in most Western countries during the large-scale educational expansion in the second half of the $20^{\text {th }}$ century. Other studies, however, have observed decreases in IEO in several countries (Ballarino et al. 2009; Breen et al. 2009).

In order to explain the observed trends in inequality, Raftery \& Hout (1993) developed the Maximally Maintained Inequality (MMI) hypothesis. MMI states that decreases in IEO at a given level of education will only occur when the demand from advantaged groups has been saturated. For example, as high school attendance becomes universal, class-based differences in the transition to high school will, by definition, disappear. At this point, however, children from more advantaged families are likely to seek a tertiary degree in order to maintain their relative advantage. As a result, educational inequality shifts from lower- to higher-level transitions as societies move from elite to mass education. If the MMI hypothesis holds, we would expect IEO to decline only for transitions where attendance from highstatus children has become (almost) universal, and to remain stable in all other cases.

The aforementioned perspectives were developed to explain historical trends in Europe and the US, and may thus not be applicable to transition societies such as China. How the transition from socialism to capitalism affects social mobility remains ambiguous, and market transition theory (Nee 1989) is largely silent on the topic. On the one hand, inequality can be assumed to increase as socialist policies that favour the working classes are replaced by market-based allocation. On the other hand, social stratification is far from absent in socialist economies, and marketization and related economic developments may bring new opportunities for meritocratic advancement, in line with the predications from modernization theory (Jackson and Evans 2017). Empirical evidence suggests that educational inequality is likely to increase in the immediate aftermath of the transition, although the medium- to long-term effects remain unclear. Important studies in this regard include Torche (2005, 2010) who looked at educational stratification during a period of market reforms and economic restructuring in Latin America, and Gerber (2000), who analyzed trends in IEO in post-Soviet Russia. 
Both observed (temporary) increases in IEO resulting from a combination of economic crisis, political instability and the radical educational reforms pursued by the new authorities.

In contrast to the abovementioned cases, China's economic reforms were tightly managed by the central government and did not involve a major economic downturn. Nevertheless, they are likely to have important implications for educational stratification. Market transition theory suggests that educational credentials will become an increasingly important asset as the economic allocation mechanism shifts from state to the (labour) market (Nee 1989; Szelenyi and Kostello 1996). Various studies have shown that returns to education increased exponentially during China's market transition process (Li 2003; Zhou 2014). When education becomes an increasingly important determinant of family income and social status, this is likely to strengthen the intergenerational transmission of educational attainment.

Particularly in the Chinese case, however, market mechanisms were phased in gradually and the state continues to play an important role in the allocation of resources, including educational credentials (Bian and Logan 1996). As a result, politically influential groups may use their power and connections to obtain various advantages for their children, including admission to elite schools and colleges (Yang and Chen 2016). Another particular aspect of social stratification in China is the household registration or hukou system. Introduced in 1955 , the hukou system limits geographic mobility and assigns rural residents a lower level of public services and benefits, effectively creating an institutionalized form of social inequality (Wu and Treiman 2004). Regional differences in the quality and availability of schools are part of the reason for the massive rural-urban disparity in educational attainment, which has increased further in recent decades (Hao, Hu, and Lo 2014; Tam and Jiang 2015; Wu 2012). In studying educational stratification in China, it is therefore important to take into account the political status and household registration of the household of origin, in addition to traditional measures such as parental education. 


\section{BACKGROUND: THE CHINESE EDUCATION SYSTEM}

China's education system is characterized by an unusually high degree of standardization and uniformity. In spite of massive social, economic and political upheavals, its underlying structure has remained virtually unchanged since the mid-20 th century (Treiman 2013). Children usually start primary school, which takes six years, at the age of six or seven. Similar to the American system, primary school is followed by three years of junior high school (JHS), three years of senior high school (SHS), and three or four years of college. Most children leave the education system before they reach the more advanced levels, however (see Figure 1). As an illustration, out of the sample of individuals born between 1960 and 1987, only $28 \%$ had completed senior high school, and only $13 \%$ had obtained a college degree. The following section will provide a brief chronological overview of the development of educational policy in China, focusing in particular on policy objectives related to access and IEO.

\section{9-1977: The Maoist period}

During the Communist era (1949-1978) the focus of educational policy fluctuated between the dual objectives of egalitarianism and developing the human capital necessary for social and economic advancement. This reflected a struggle within the party state between ideological 'radicals' and more pragmatic 'reformers' (Andreas 2009; Ross and Pepper 1997; Tsang 2000). While the former saw education as a tool for levelling class differences and instilling a revolutionary mentality, the latter emphasized the need for technocratic expertise and selection on ability.

In line with the egalitarian objective, the focus of educational expansion during the Communist era was on elementary schooling, and children from desirable class backgrounds (peasants and workers) were sometimes given preferential treatment in accessing higher education (Hannum, Park, and Cheng 2007; Tsang 2000). The focus on class levelling was most pronounced during the Cultural Revolution (1966-1976), a period of great social upheaval during which universities were closed and urban students were 'sent down' to work in the countryside. Although the Cultural Revolution policies expanded access to basic education in rural areas, the quality of schooling was often poor (Andreas 
2004; Deng and Treiman 1997). Various studies have shown that IEO based on social origin was low during the Communist era, both compared to other countries and to the period immediately following the transition (Li 2006; Zhou et al. 1998). The impact of family background on educational outcomes was particularly depressed during the Cultural Revolution, although it was never fully eliminated (Deng and Treiman 1997).

\section{8-present: The Reform Era}

The Cultural Revolution ended with the death of Mao and the arrest of many radical leaders in 1976. The reformist Party leadership under Deng Xiaoping soon embarked on a fundamentally different course, dismantling the planned economy and initiating the transition to a market-based economic system. The impact of the market transition on educational policy can hardly be underestimated. The reformers "not only repudiated the radical education policies of the Cultural Revolution, but completely disavowed class levelling in the cultural field, freeing the party from a doctrinal commitment that had complicated its educational policies since 1949" (Andreas 2009:224). The ideological goals of the Maoist period were replaced by the principles of meritocracy, efficiency and technical expertise. Following Deng Xiaoping's call to "respect knowledge and talent" (1977), the SHS entrance examination (zhongkao) and college entrance examination (gaokao) were (re)instated. These exams not only determine whether students can proceed to senior high and post-secondary education, they also affect the type of institution students are eligible for, with more prestigious schools and colleges demanding higher test scores. At the same time, the main focus of educational policy shifted from providing broad-based access to training a new class of technical experts (Ross and Pepper 1997; Tsang 2000).

A major implication of the post-1978 reforms was the increasing horizontal differentiation of the educational system. Essentially, the reformers envisioned a bifurcated educational system, "with a small 'elite' sector to train the first-class scientists and engineers (...) alongside a large, 'mass' sector that is expected to provide basic educational skills, with the possibility of additional vocational training, for the majority" (Rosen 1985). This was accomplished through the (re-) establishment of key point 
secondary schools, which purposely prepare the most promising students for the college entrance examination. Key point schools have better funding and more qualified teaching staff, and admission is limited to those with very high test scores (Park et al. 2015; Ye 2015). At the same time, an increasing number of students was channelled into vocational senior secondary schools, which provide much lower prospects of college admission ${ }^{1}$ (Tsang 2000). High demand in combination with the crucial importance of standardized entrance tests created a system geared towards exam preparation. Testbased teaching permeates all the way down to the primary level, and students with little prospect of excellent test scores frequently become demotivated or leave the education system altogether (Andreas 2004; Hannum, An, and Cherng 2011; Jia and Ericson 2017).

A second reform involved the gradual marketization of the educational system. Since the early 1980s, a process of decentralizing educational funding has taken place in the name of creating a more diversified revenue base (Tsang 2000). In practice, this created increased disparities in the quality and availability of education between regions, as well as between rural and urban areas within regions (Hannum and Wang 2006). Marketization also increased the importance of tuition fees as a component of educational financing. Although basic education (primary and JHS) is largely free, cost can constitute a substantial barrier to entry for SHS and higher education. Tuition fees have increased dramatically since the early 1990s, and are now very high both in international comparison and relative to household income. For example, it was estimated that for a family living at the poverty line, the annual cost of sending a child to SHS was equivalent to 4 times the annual per capita income, while university costs over 9 times that amount (Wang et al. 2011).

Marketization has also created opportunities for wealthy parents to directly influence their children's educational outcomes. For example, parents may pay a substantial fee to allow their child to attend school in another district, or to attend a key point school without obtaining the required test score (Tsang 2000). Parents can also decide to avoid the public system altogether and send their child to a private school. Although the core of the education system remains government-run, private schools became a common phenomenon during the 1990s, particularly at the secondary and tertiary level. In 
many cases, they constitute a backup plan for affluent students that do not have the required grades to enter prestigious public schools and colleges (Jia and Ericson 2017).

The initial effect of the post-1978 reforms was a temporary decline in enrolment rates, particularly at the secondary level, as substandard rural schools established during the Cultural Revolution were closed (Andreas 2009; Treiman 2013). Another factor that contributed to the decline in (rural) enrolment rates was the introduction of the household responsibility system, in which collective farming was replaced by individual family plots. An unintended side-effect of this reform was that it increased the opportunity cost of sending teenage children to school (Wu and Zhang 2010). The reduction in rural enrolment was only a minor deviation from an otherwise linear trend in educational expansion, however. The economic success of the market reforms fuelled the need for skilled labour, and thereby the demand for education (Tsang 2000). Educational attainment increasingly became an essential marker of social status and the key to success in the new market economy.

Educational expansion during the early reform period was largely focused on primary and junior secondary education, with comparatively less expansion at the senior secondary and tertiary level (Treiman 2013). In line with the bifurcated approach, educational officials had long worried that broadening access to these higher levels would lead to a drop in quality. As a result, intense competition over the limited number of spaces emerged. Pressured by economic imperatives and an increasing demand for higher education from the emerging middle class, the State Council ushered in a new phase of educational reforms with its 1998 'Plan for Revitalizing Education in the Twenty-First Century', which largely focused on expanding tertiary enrolment.

As with the previous wave of reforms, the higher education expansion was driven by the need for human capital development rather than considerations of access and equity (Yeung 2013). In addition to creating new universities and vocational colleges, the government instructed existing institutions to massively increase their annual intake of students. The result was a rapid increase in tertiary enrolment rates. The annual number of higher education entrants increased from 1.1 million in 1998 to 5.0 million 
in 2005 and 7.2 million in 2014 (National Bureau of Statistics of China 2015). The increase in enrolment was not accompanied by a corresponding increase in public funding, however, so that colleges were forced to drastically increase tuition and other fees to cover the cost of the expansion (Bai 2006). Because elite universities retained relatively high levels of government funding, this has led to a peculiar situation in which the cost of higher education is inversely related to its quality (Li 2007).

\section{Educational inequality in the Reform Era}

How the various educational reforms implemented since 1978 affected educational stratification is the key question this study seeks to answer. A number of studies suggested that IEO increased in the period immediately following the 1978 market reforms (Deng and Treiman 1997; Li 2006; Zhou et al. 1998). Zhou et al., concluded that reform "appears to have favoured the most advantaged groups in the population: the children of high-rank cadres and professionals, residents of large cities, and men more than women" (1998:217). This is hardly surprising because the reforms followed the Cultural Revolution, a unique experiment in class levelling in education. We know comparatively less about the trends in educational mobility during the market transition process, although a recent study showed that the intergenerational persistence in years of education has increased somewhat, even as the variation in educational outcomes reduced (Golley and Kong 2016). It is well known, however, that trends in the persistence of final educational attainment conflate educational expansion with trends in IEO, which is why most inequality scholars use the educational transition model (Mare 1980). Studies following this approach in the Chinese context have generally focused on particular transitions and relatively brief periods, however. For example, Xiaogang Wu (2010) suggested that household registration and fathers' socio-economic status became increasingly important determinants of high school enrolment and transitions between 1990 and 2000. Using more recent data, Yeung (2013), found a decreasing effect of fathers' education on SHS transitions and an increasing effect on the transition to college following the 1998 higher education reforms. In order to fully understand the implications of China's market transition for educational inequality, there remains a need for a 
comprehensive assessment of the effects of social origin across all relevant transitions between cohorts that completed their education during different phases of the market transition process, which is what this study seeks to provide.

\section{METHOD}

\section{Data}

All analyses are based on Wave 2 (2012) of the China Family Panel Studies (CFPS), a high-quality, nationally representative survey managed by Peking University. In 2012, the CFPS covered 34,447 adults in 13,453 households in 25 provinces. The CFPS data were collected using computer-assisted personal interviews, with extensive quality checks both during and after the interview. Surveyors tried to interview each adult household member, including members that had migrated temporarily for reasons such as work. Participation rates were outstanding: the response rate in 2010 was $81.3 \%$ at the household level and $84.1 \%$ on the individual level, and $85.1 \%$ of households and $80.6 \%$ of individuals were successfully re-interviewed in 2012 (Xie and Hu 2014:13). All analyses are weighted to account for sampling design and non-response.

The CFPS provides detailed measures of respondents' educational attainment, as well as other basic demographic information. Moreover, the 2012 round contains detailed retrospective measures of social origin, including parental education level, occupation, and political status when the respondent was 14 years old.

This study covers individuals born between 1960 and 1987 (aged between 25 and 52 in 2012). Whereas most people born before 1960 would have completed their educational career when the market reforms started, those born after 1987 might still be in school by the time of the survey. The full sample contains 16,422 individuals. Some of the covariates contained a small number missing or unknown values, particularly parents' educational attainment (3.9\%) and parents' party membership (2.3\%). I therefore applied multiple imputation using chained equations. This procedure created five imputed 
datasets, using an imputation model that included all analytical variables as well as a number of auxiliary variables. Pooled estimates were calculated using Stata's mi prefix (StataCorp, 2015).

\section{Measures}

Table 1 provides descriptive statistics for each of the analytical variables, by cohort. The outcome variable, educational attainment of respondents, is measured using a 5-point scale based on the International Standard Classification of Education (ISCED): no degree (1), completed primary school (2), completed Junior High School (JHS) (3), completed Senior High School (4), and completed college or higher (5).

My first variable of interest is parents' educational attainment when respondents were aged 14, measured on the same 5-point ISCED scale. Parents' education serves as a proxy for household income and socio-economic status. It also reflects the 'educational resources' available in a household, which relate to a supportive home learning environment as well as parental guidance in educational decisionmaking (Bukodi and Goldthorpe 2013). In the interest of parsimony, I applied the dominance approach instead of assessing the effect for fathers and mothers separately. Table 1 suggests that parental education increased substantially across cohorts, in line with overall educational expansion.

The second variable of interest is household registration or hukou status when the respondent was 12 years old. Wu demonstrates a persistently negative effect of rural household registration status on high school transitions as well as on overall years of schooling attained (2012). Moreover, it was observed that the quality and availability of education differs strongly between rural and urban areas (Tam and Jiang 2015). Although it is possible that some children with rural household registration grew up in urban areas (particularly in recent years), their rural hukou would have assigned them to different and typically inferior schools.

In a state-controlled market economy such as China, it is useful to add political capital as a further element of parental background. In reform-era China political connections continue to provide substantial benefits, which may result in educational advantages for children of party members 
(Andreas 2009; Yang and Chen 2016). I therefore included a dummy variable indicating whether any parent was a Communist Party member when the respondent was 14 years old. In each cohort, between 17 and $22 \%$ of respondents had at least one parent that was a Party member (Table 1 ).

Finally, I look at gender differences in educational opportunity. Chinese families have a long history of differential investment in male and female children, in line with patriarchal and patrilineal Confucian family norms. As in most modernizing societies, however, gender gaps in schooling have disappeared or even reversed among the most recent cohorts (Hannum 2005; Hannum and Xie 1994).

\section{Analytical approach}

The classic tool for analysing inequality of opportunity in education, and particularly its development over time, is the sequential transition model (Mare 1980). Transition models compare the impact of parental background or other ascribed characteristics at each educational transition. In this study, I look at each of the four key transitions described in Figure 1: completing primary (1), completing JHS conditional on completing primary (2), completing SHS conditional on completing JHS (3) and obtaining a college degree on completing SHS $(4)^{2}$. The sequential transition model is particularly applicable in this case because the Chinese education system is vertically structured, and completing the previous level is a precondition for entering the next. It is therefore possible to deduce each respondent's educational path by looking at the highest level attained. For example, a respondent with a JHS degree would have passed the transition to primary and to JHS, but failed to make the transition to SHS. As a result, he or she would no longer be in the risk set for obtaining a tertiary degree.

I compare cohorts rather than periods to assess temporal trends in IEO, for a number of reasons. First, late school enrolment and adult education are common features of the Chinese education system, and both are strongly related to social origin (Fan 2016; Hannum et al. 2011). A period-based approach based on 'standard' ages of school completion might therefore underestimate lifetime educational attainment and misinterpret the degree of educational mobility. Second, path dependency means that 
higher-level transitions may be affected by policies in place during early phases of the educational career, a pattern that is more adequately captured using a cohort approach. I distinguish between five birth cohorts: 1960-64 (Cohort 1), 1965-69 (Cohort 2), 1970-74 (Cohort 3), 1975-79 (Cohort 4) and 1980-87 (Cohort 5). They are described in more detail in the following section.

By calculating separate models for each cohort and transition, covariates and intercepts are allowed to vary freely between cohorts, reflecting the changing nature of IEO over time. The resulting odds ratios are independent of educational expansion (e.g. an overall increase in school attendance), and thus reflect the degree of relative educational inequality. Strictly speaking, the odds ratios cannot be compared across cohorts, however, because the comparison could be affected by between-group differences in residual variation (unobserved heterogeneity) (Allison 1999; Mood 2010).

In addition to the odds ratios, I therefore also present plots of origin-specific conditional transition probabilities. These plots, which are derived from the same sequential logit model, are not affected by this identification problem and provide an easily interpretable picture of cohort trends in educational expansion as well as absolute educational inequality (Blossfeld, Blossfeld, and Blossfeld 2015). In combination, these two metrics provide a comprehensive picture of between-group changes in IEO across cohorts (Kröger and Skopek 2017).

Finally, I analyze the effect of cumulative inequality across transitions by looking at the unconditional probability of attaining 1) at least a senior high school degree and 2) a college degree, for various combinations of family background variables.

\section{RESULTS}

\section{Cohort differences in educational attainment and transition rates}

Figure 2 shows at which point in historical time each of the five cohorts identified in this study would have reached the key educational transitions, provided they had followed a 'regular' educational 
career. Their overall levels of educational attainment, and the derived transition rates, are presented in Table 1.

Cohort 1 entered primary school and JHS during the Cultural Revolution, and it therefore benefited from the grassroots educational expansion that took place during this period, particularly in rural areas. Table 1 shows that this cohort had higher transition rates to primary school, JHS and SHS than the two cohorts that followed it, but much lower transition rates to higher education.

Cohort 2 obtained most of its secondary education in the chaotic period immediately following the start of the market transition. During this period, many of the new rural schools that were established as part of the Cultural Revolution were closed down, leading to a sharp decline in secondary enrolment rates. It progression rate to college was much higher than for the previous cohort, however (see Table 1).

Cohort 3 was the first to start its educational career during the reform period, and thus experience the full force of the market-oriented educational reforms. Its progression rates to JHS and SHS recovered somewhat compared to the preceding cohort, but still remained below those observed in Cohort 1 .

Cohort 4 is much smaller than the preceding cohorts, which is partially the result of government efforts to reduce fertility rates during the 1970s. This may have relieved some of the demand-side pressure on the educational system and led to higher transition rates, as suggested by Table 1 . Moreover, this cohort would be the first to be affected by the dramatic increase in tuition fees for SHS and college, which started in the early 1990s.

Cohort 5 (1980-1987) consists of children born after the official implementation of the fertility reduction policy (1979). As the most recent cohort, their experience reflects the current state of the Chinese education system. This cohort graduated from SHS after the start of the higher education expansion in 1998 , which is reflected in the much higher percentage obtaining a college degree $(23.5 \%$ versus $14.0 \%$ in the preceding cohort). 
The overall picture is thus a short-lived contraction followed by a gradual expansion of access to education. Table 1 also shows substantial attrition at each transition, even in the most recent cohort. As a result, the majority of students leave the education system before they reach the higher-level transitions.

\section{Inequality of opportunity in educational transitions}

Overall increases in transition rates are likely to mask substantial differences based on social origin and other ascribed characteristics. Results from the sequential logit models are presented as odds ratios (Table 2) as well as predicted conditional transition probabilities (Figures 3, 4 and 5). Whereas the odds ratios provide a measure of inequality net of educational expansion (relative inequality), differences in the conditional transition probabilities reflect the degree of absolute educational inequality. Cohort trends in conditional transition probabilities are plotted by parental education (Figure 3), by parents' party membership (Figure 4) and by household registration (Figure 5) ${ }^{3}$. While a convergence of originspecific transition probabilities would suggest a reduction in absolute inequality, divergence would suggest the opposite: increasing inequality. Moreover, the plots allow us to observe the degree of educational expansion (which would result in an overall upward trend in the transition probabilities) as well as the cohorts and transitions for which the demand from high status groups has been 'saturated'.

The first set of findings, using the entire sample as a risk set, relates to obtaining at least a primary school degree. Table 1 shows that an increasing share of respondents in each birth cohort had completed primary school, although a substantial proportion left school without an elementary degree up to the 1980 s and early 1990 s, in spite of the mandatory education law introduced in $1986^{4}$.

As primary attainment became nearly universal for younger cohorts, absolute differences in transition rates based on parents' party membership (Figure 4) and household registration (Figure 5) declined. Relative inequality appeared to increase, however, particularly for children whose parents did not have 
a primary school degree themselves (see Table 2). The apparently worsening position (in relative terms) of children with uneducated parents is probably due to the increased selectivity of this group. Whereas it constituted $54.8 \%$ of the $1960-64$ cohort, it made up only $15.7 \%$ of the $1980-87$ cohort. It is likely that the later cohort is more negatively selected on unobserved characteristics, such as geographic isolation. In other words, when a particular level of education nears universal attendance, the dropouts become an increasingly stratified group (Kröger and Skopek 2017) (this is the inverse of the 'survivor bias' in higher educational transitions described by Mare (1981) and others, discussed in more detail below).

The second transition in the Chinese school system is the completion of Junior High School (JHS). Table 1 shows that $74 \%$ of primary school graduates born between 1960 and 1964 went on to complete JHS. The transition rate dropped by more than 10 percentage points for cohort 2 , which would have entered JHS shortly after the start of the market transition, and then continued to increase to $82.7 \%$ for the most recent cohort. It is likely that this temporary contraction relates to the closure of (mostly rural) secondary schools that were set up during the Cultural Revolution, and which mainly catered for students from less advantaged social backgrounds (Andreas 2004; Treiman 2013). This hypothesis is supported by Figure 5 (T2), which shows that completing JHS was virtually universal for urban children of all birth cohorts. The post-transition decline in the transition rate thus only affected rural children, although the rural-urban gap in JHS completion decreased for subsequent cohorts. Attrition at this level is also strongly differentiated by parental education and party membership, whose effects are relatively persistent across birth cohorts (see Figures 3 and 4, as well as Table 2). For example, the gap between children with parents who were Party members and those whose parents were not in the Party was 11.7 percentage points in Cohort $1,12.3$ points in Cohort 3 and 11.9 points in Cohort 5.

Because of its relatively large risk pool and low transition rate, it could be argued that the transition to SHS is the main bottleneck in the Chinese education system (see Table 1). As a result, inequality emerging at this level will have a particularly strong effect on the final distribution of educational outcomes (Buis 2015). Figure 3 (T3), which looks at transition probabilities by parental education, 
shows a drop in the transition rate for Cohort 2 , similar to the one observed in the transition to JHS. In this case, however, the subsequent increase in transition rates is accompanied by a divergence of the origin-specific trends, e.g. an increase in (absolute) educational inequality. In Cohort 1, having parents with a college degree improved the probability of completing SHS by 24 percentage points, compared to having parents with only a primary school degree (70 vs. $46 \%)$. In the last cohort, this gap had increased to 53 percentage points (92 vs 39\%). The odds ratios presented in Table 2 confirm this pattern, showing substantial increases in the effect of parental education, net of an overall increase in SHS completion. Stratification by parental education is compounded by rural-urban differences and, to a somewhat smaller extent, differences by party membership. The rural-urban gap in the transition to SHS is particularly striking: it increased from 27 percentage points (36\% vs. 63\%) in Cohort 1 to 42 percentage points (44\% vs. $86 \%$ ) in Cohort 5 (see Figure 5). Increasing stratification at the transition to SHS is in line with findings by Wu (2010) and Tam \& Jiang (2015).

There may be several reasons for the increasing importance of family background in completing SHS. Being the first (nominally) non-compulsory level of education, senior high schools typically require minimum entrance examination scores and charge tuition fees. Moreover, while tuition fees for compulsory levels of schooling have been gradually abolished, those for SHS (which are often designed as boarding schools) have increased substantially in recent decades, making a senior high school degree almost unaffordable for children from low-income families (Wang et al. 2011). Finally, Tam \& Jiang (2015) showed that post-reform expansion at the SHS level was mainly concentrated in already advantaged urban areas.

The final transition (T4) refers to the completion of a college degree, conditional on completing SHS. Entry to higher education, particularly the most prestigious universities, is highly competitive and conveys important social and economic rewards (Wu 2017). With few exceptions (e.g. private colleges or studying abroad), the available options are determined by one's College Entrance Examination score. Although the progression rate into tertiary education has increased as a result of the 1998 reforms, a substantial number of SHS graduates are still sorted out each year, and many repeat the 
entrance exam for several years until they obtain the required score (Andreas 2004). In my sample of SHS graduates born between 1960 and 1987, only 46\% proceeded to obtain a college degree.

Both the odds ratios (Table 2) and the predicted probabilities (Figure 3, 4 \& 5) show that origin-based differences in the transition to higher education are less pronounced in comparison to earlier transitions. Particularly in the first three cohorts, the association between college graduation and hukou, parental education, and parents' party membership was small and mostly not significant. Does this mean that access to higher education in China is relatively egalitarian? That would be a questionable conclusion, for a number of reasons. First, the risk set for the transition to higher education consists of those that have successfully completed the previous three transitions. Even for the most recent cohorts, this group is a relatively small (see Table 1 ) as well as a highly socially selected, as we have seen in the previous analyses. If children from less advantaged social origins are sorted out early on in the transition process, higher education institutions no longer 'need' to select on the same characteristics to obtain a high-status student body (Shavit, Yaish, and Bar-Haim 2007:47).

Moreover, in the two most recent cohorts we can observe an increasing importance of social origin, particularly in the form of a widening rural-urban gap (Figure 5). The increasing disadvantage of rural students has been well documented elsewhere, and is related to widening disparities in access and quality earlier on in the educational pipeline, particularly at the SHS level (Loyalka et al. 2017; Tam and Jiang 2015; Yeung 2013). Consequently, the 1998 higher education expansion was of little value to rural students, most of whom would have left the system before reaching the final transition.

Finally, an important aspect of IEO that has not been discussed thus far relates to the role of gender. Gender differences used to be particularly pronounced in the transition to primary school and JHS, but they have narrowed considerably across cohorts (see Annex Figure 1). For the most recent cohort (1980-78) there is virtually no gender gap at any of the lower transitions, and women even hold a slight advantage in the transition to college. This is in line with what has been found in previous studies (Hannum 2005; Hannum and Xie 1994). 


\section{Cumulative inequality of opportunity in educational attainment}

Thus far, we have looked at the probability of making a particular transition conditional on completing the previous one. Although this approach has a number of well-known advantages, it also has at least two drawbacks. First, as noted by Mare himself $(1980,1981)$, educational expansion may lead to increased inequality even if the underlying stratification mechanisms remain unchanged, because the risk set at higher transitions becomes more heterogeneous on unobserved characteristics such as ability (see also Buis 2011; Cameron and Heckman 1998). In other words, if access to schooling is highly restricted, children from less conducive social origins who reach higher transitions are probably so talented or motivated that it cancels out their initial disadvantage. As access to education expands and the pool of high school graduates starts to resemble the general population more closely, social selectivity is reduced and the effect of social origin reappears 5 . Second, a focus on individual transitions and predictors may mask the cumulative effect of various aspects of social origin throughout the educational career (Buis 2015; Torche 2010). Cumulative advantage may occur through various mechanisms, including path dependency and school effects (DiPrete and Eirich 2006).

For these reasons, I looked at cohort trends in the unconditional chances of attaining 1) at least a SHS degree and 2) a college degree, for three different combinations of family:

- Disadvantaged: rural household registration, parents with no degree, not party members

- Average: rural household registration, parents with JHS degree, not party members

- Advantaged: urban household registration, parents with SHS degree, party members

The findings (presented in Figure 6 and Annex Table 1) clearly indicate a pattern growing cumulative inequality in educational attainment, particularly in obtaining a college degree. For example, the predicted probability of attaining at least a senior high school SHS for someone from a disadvantaged household was $13 \%$ in Cohort 1 , and declined to $11 \%$ in Cohort 5 . Meanwhile, the corresponding figures for advantaged households increased from $71 \%$ to $90 \%$. Similarly, advantaged respondents increased their chances of obtaining a college degree by 37 percentage points (33\% to $70 \%$ ), whereas 
disadvantaged respondents improved by merely 3 percentage points. It must be noted, of course, that the number of individuals belonging to advantaged households increased across cohorts, because of the changing distribution in family background (particularly parental education).

\section{DISCUSSION}

The objective of this article was to assess the changing role of social origin in the process of educational attainment in China, with a focus on changes that occurred during the reform period (1978-present). This period was characterized by a gradual expansion of educational opportunities, but also by rapidly increasing socio-economic inequality.

The CFPS provides a unique opportunity to look at detailed trends in IEO in a large and nationally representative Chinese sample. The findings show that family background, particularly hukou origin and parental education, have increased as a stratifier during the market transition period. IEO emerges at each transition, and is particularly pronounced when looking at the cumulative effect of social origin throughout the educational career. This suggests that educational opportunities have become more unequally distributed, in spite of overall educational expansion (see also Golley and Kong 2016; Wu 2010). Inequality not only increased in the chaotic period immediately following the 1978 transition, it continued to increase throughout the transition process, up to the present day. Contrary to market transition theory, I did not observe a general decline in the importance of parents' political status. Instead, I found a small but persistent advantage of party members' offspring across cohorts.

Particularly for children from less privileged social backgrounds, the Chinese school system can be perceived as a hurdle race, in which a high number of participants drop out at each barrier. IEO particularly increased at the transition from junior to senior high school, where the degree of attrition is highest. Although IEO in access to higher education was comparatively less pronounced, the sorting that took place at earlier transitions meant that most disadvantaged students never managed to reach this stage. These findings correspond to a particularly strong form of the MMI hypothesis, in which high-status groups not only maintained but improved their relative advantage in the more advanced 
educational transitions. The logic behind the MMI hypothesis is closely related to social reproduction theory. Because of their superior resources and knowledge of the educational system, former elites are best positioned to capitalize on the new opportunities for social advancement provided by educational expansion. The gains in absolute educational attainment made by the lower socioeconomic strata are illusive in comparison, particularly when we consider education to be a positional good.

The institutionalized discrimination inherent in the household registration system is a unique feature of the Chinese stratification system (Wu and Treiman 2007). While hukou-based differences declined at the transition to primary and JHS, which was virtually universal for urban children, they increased at the transition to SHS and, to a lesser extent, college. Rural Chinese children have to overcome a triple structural disadvantage in the competition for higher educational degrees: attending lower quality schools, they face higher relative costs and less favourable admission criteria than their urban counterparts (Tam and Jiang 2015).

The changes in IEO are remarkable, particularly when we take into account that the cohorts observed in this study span only 27 years. In the comparative literature on IEO, which now covers most developed and emerging economies, increases in inequality during educational expansion are an uncommon phenomenon. The only cases in which similar patterns have been observed are post-Soviet Russia (Gerber 2000) and Latin America in the 1980s (Torche 2010). In both cases, increases in IEO were the result of profound economic crises which depressed educational demand and increased the relative cost of schooling. Post-reform China, however, is the only known case in which expanding inequality took place in a context of rapid economic growth and rising living standards. It is therefore unlikely that the observed patterns arise from socio-economic differences in educational demand or expectations. Various studies have shown that educational aspirations are very high in China, regardless of socio-economic status (Liu and Xie 2015). Instead, I suggest that expanding inequality result from a combination of market-based educational reforms, increasing returns to education and massive increases in wider social and economic inequality. 
During the Maoist era (1949-1978), income inequality was comparatively low and children from upper class origins were often blocked from progressing through the educational system, as part of a deliberate effort to disrupt the intergenerational reproduction of inequality. These attempts were abandoned with the market transition, and replaced by a system based on achievement selection. Other educational reforms implemented during the market transition period involved the establishment of elite schools and colleges, a rapid increase in tuition fees and an expansion of private schooling. Each of these reforms has provided privileged parents with new opportunities to ensure their offspring's educational success. Educated parents are more likely to provide their children with the resources to do well in the system of competitive examinations that determines post-reform educational outcomes (Andreas 2004; Hannum et al. 2011). Even if their children do not manage to obtain the required grades to enter prestigious key point schools, they have the option to send them to expensive private schools or even abroad. For the poorest households, on the other hand, obtaining advanced education has simply become unaffordable.

The effect of marketization in the educational system, which elevated the importance of family resources, was compounded by the surge in income inequality and in returns to education, both of which took place in approximately the same period (Xie and Zhou 2014). Income inequality amplified the disparity in ability to pay for education between different socio-economic strata, placing less fortunate households at an increasing competitive disadvantage. At the same time, increasing returns to education raised the stakes, intensifying the competition for the limited supply of higher educational degrees (Li 2003). It is generally assumed that increased competition has a negative effect on equality of opportunity (Gerber 2000).

These findings show that educational stratification can increase even during periods of continuous educational expansion. In China, educational expansion has helped elites to entrench their advantaged position and strengthened the intergenerational reproduction of inequality. Educational inequality, income inequality and increasing returns to education have become a mutually reinforcing process, laying the foundation for future socio-economic stratification. Increasing educational inequality may 
have a negative impact on economic growth (Yu et al. 2015). The findings also run counter to the government's 'Harmonious Society' agenda, which seeks to equalize opportunities and reduce socioeconomic disparities. Both policymakers and opinion leaders have referred to the Confucian ideal of meritocracy to explain and justify increasing levels of social inequality in contemporary China (Whyte and Im 2014). This study shows that such assertions have become increasingly untenable.

The size and representativeness of the CFPS sample ensures that these findings can be generalized to the Chinese population. Nevertheless, a number of limitations should be taken into account when interpreting the findings. First, although the study focused on the association between social origins and educational outcomes, it did not address the mechanisms through which such associations arise. Future research could look at the distinction between primary ('ability') and secondary ('choice') effects in the intergenerational transmission of education (Boudon 1974), as a well as the role of institutional features such as tuition fees and entrance examinations. Moreover, further inequalities may manifest themselves when looking at selection within education levels, for example between regular high schools and key point schools, or between elite universities and less selective colleges (see e.g. Park et al. 2015; Ye 2015). Finally, for reasons mentioned earlier, it is difficult to link changes in IEO across cohorts to period-specific educational policies. It is possible, for example, that earlier cohorts benefited from the 1998 college expansion by entering college at a later stage in life.

These limitations notwithstanding, the study contributes to our understanding of educational inequality in a number of ways. First, it provides robust evidence of substantial increases in inequality of opportunity during China's market transition, particularly at the crucial transition to senior high school. Second, it shows a strong and increasing cumulative effect of family background throughout the educational career, which is mainly caused by origin-specific attrition at each transition. Finally, it highlights the importance of looking at absolute as well as relative levels of inequality in interpreting the findings from educational transition models. 


\section{NOTES}

${ }^{1}$ Andreas (2004) argued that many of these schools were vocational in name only, and actually offered a lower-quality version of the general academic curriculum.

${ }^{2}$ Some studies define an educational transition as starting, rather than completing, a given level of education. For reasons of parsimony and because of the signalling function of educational degrees, I present findings based on completed levels of schooling only. A sensitivity analysis with the alternative specification did not give reason to modify the conclusions presented in this paper.

${ }^{3}$ Trends by gender are presented in the Annex Figure 1

${ }^{4}$ This is in line with official statistics, which show that primary school enrolment only reached nearly universal levels by the end of the $20^{\text {th }}$ century (Treiman 2013). It is important to note that many of those without a primary school certificate have completed at least a few years of schooling.

${ }^{5}$ Others have argued, however, that ability is largely endogenous to the mechanism linking social origins to educational outcomes (Shavit et al. 2007). 


\section{BIBLIOGRAPHY}

Allison, Paul D. 1999. "Comparing Logit and Probit Coefficients Across Groups." Sociological Methods \& Research 28(2):186-208.

Andreas, Joel. 2004. "Leveling the Little Pagoda: The Impact of College Examinations, and Their Elimination, on Rural Education in China." Comparative Education Review 48(1):1-47.

Andreas, Joel. 2009. Rise of the Red Engineers: The Cultural Revolution and the Origins of China's New Class. Stanford University Press.

Bai, Limin. 2006. “Graduate Unemployment: Dilemmas and Challenges in China's Move to Mass Higher Education." The China Quarterly 185:128-44.

Ballarino, Gabriele, Fabrizio Bernardi, Miguel Requena, and Hans Schadee. 2009. "Persistent Inequalities? Expansion of Education and Class Inequality in Italy and Spain." European Sociological Review 25(1):123-38.

Bian, Yanjie and John R. Logan. 1996. "Market Transition and the Persistence of Power: The Changing Stratification System in Urban China." American Sociological Review 61(5):739-58.

Blossfeld, Pia N., Gwendolin J. Blossfeld, and Hans-Peter Blossfeld. 2015. “Educational Expansion and Inequalities in Educational Opportunity: Long-Term Changes for East and West Germany." European Sociological Review 31(2):144-60.

Boudon, Raymond. 1974. Education, Opportunity, and Social Inequality; Changing Prospects in Western Society. Wiley.

Bourdieu, Pierre and Jean-Claude Passeron. 1970. Reproduction in Education, Society and Culture. 2nd ed. London: Sage.

Breen, Richard and Jan O. Jonsson. 2005. "Inequality of Opportunity in Comparative Perspective: Recent Research on Educational Attainment and Social Mobility." Annual Review of Sociology 31(2005):223-43.

Breen, Richard, Ruud Luijkx, Walter Müller, and Reinhard Pollak. 2009. "Nonpersistent Inequality in Educational Attainment: Evidence from Eight European Countries." American Journal of Sociology 114(5):1475-1521.

Buis, Maarten L. 2011. "The Consequences of Unobserved Heterogeneity in a Sequential Logit Model." Research in Social Stratification and Mobility 29(3):247-62.

Buis, Maarten L. 2015. "Not All Transitions Are Equal: The Relationship between Effects on Passing Steps in a Sequential Process and Effects on the Final Outcome." Sociological Methods \& Research 1-33.

Bukodi, Erzsebet and John H. Goldthorpe. 2013. “Decomposing 'Social Origins': The Effects of Parents' Class, Status, and Education on the Educational Attainment of Their Children." European Sociological Review 29(5):1024-39. 
Cameron, Stephen V and James J. Heckman. 1998. "Life Cycle Schooling and Fynamic Selection Bias: Models and Evidence for Five Cohorts of American Males." NBER Working Paper 6385.

Coleman, James S. 1967. "The Concept of Equality of Educational Opportunity." Harvard Educational Review 2(4).

Deng, Zhong and Donald J. Treiman. 1997. "The Impact of the Cultural Revolution on Trends in Educational Attainment in the People's Republic of China." American Journal of Sociology 103(2):391-428.

DiPrete, Thomas A. and Gregory M. Eirich. 2006. "Cumulative Advantage as a Mechanism for Inequality: A Review of Theoretical and Empirical Developments." Annual Review of Sociology 32(1):271-97.

Fan, Wen. 2016. "Education Delayed but Not Denied: The Chinese Cultural Revolution Cohort Returning to School." Advances in Life Course Research (Online First).

Gerber, Theodore P. 2000. "Educational Stratification in Contemporary Russia: Stability and Change in the Face of Economic and Institutional Crisis." Sociology of Education 73(4):219-46.

Gerber, Theodore P. and Michael Hout. 1995. "Educational Stratification in Russia During the Soviet Period." American Journal of Sociology 101(3):611-60.

Golley, Jane and Sherry Tao Kong. 2016. "Inequality of Opportunity in China's Educational Outcomes." China Economic Review.

Hannum, Emily C. 2005. “Market Transition, Educational Disparities, and Family Strategies in Rural China: New Evidence on Gender Stratification and Development." Demography 42(2):275-99.

Hannum, Emily C., Xuehui An, and Hua-Yu Sebastian Cherng. 2011. "Examinations and Educational Opportunity in China: Mobility and Bottlenecks for the Rural Poor." Oxford Review of Education 37(2):267-305.

Hannum, Emily C., Albert Park, and K. Cheng. 2007. "Introduction: Market Reforms and Educational Opportunity in China." Pp. 1-23 in Education and Reform in China.

Hannum, Emily C. and Meiyan Wang. 2006. "Geography and Educational Inequality in China." China Economic Review 17(3):253-65.

Hannum, Emily C. and Yu Xie. 1994. "Trends in Educational Gender Inequality in China: 1949-1985." Research in Social Stratification and Mobility 13:73-98.

Hao, Lingxin, Alfred Hu, and Jamie Lo. 2014. "Two Aspects of the Rural-Urban Divide and Educational Stratification in China: A Trajectory Analysis." Comparative Education Review 58(3):509-36.

Ishida, Hiroshi, Walter Müller, and John M. Ridge. 1995. "Class Origin, Class Destination, and Education: A Cross-National Study of Ten Industrial Nations." American Journal of Sociology 101(1):145-93. Jackson, Michelle and Geoffrey Evans. 2017. "Rebuilding Walls: Market Transition and Social Mobility in the Post-Socialist Societies of Europe." Sociological Science 4:54-79. 
Jia, Qiong and David P. Ericson. 2017. "Equity and Access to Higher Education in China: Lessons from Hunan Province for University Admissions Policy." International Journal of Educational Development 52:97-110.

Knight, John, Terry Sicular, and Ximing Yue. 2013. "Educational Inequality in China: The Intergenerational Dimension." Rising Inequality in China: Challenges to a Harmonious Society.

Kröger, Hannes and Jan Skopek. 2017. "Logistic Confusion - An Extended Treatment on Cross-Group Comparability of Findings Obtained from Logistic Regression." Working Paper (April).

Li, Chunling. 2006. Sociopolitical Change and Inequality in Educational Opportunity: Impact of Family Background and Institutional Factors on Educational Attainment (1940-2001). Vol. 38.

Li, Haizheng. 2003. "Economic Transition and Returns to Education in China." Economics of Education Review 22(3):317-28.

Li, Wenli. 2007. "Family Background, Financial Constraints and Higher Education Attendance in China." Economics of Education Review 26(6):724-34.

Liu, Airan and Yu Xie. 2015. “Influences of Monetary and Non-Monetary Family Resources on Children's Development in Verbal Ability in China." Research in Social Stratification and Mobility 40:59-70. Loyalka, Prashant, James Chu, Jianguo Wei, Natalie Johnson, and Joel Reniker. 2017. "Inequalities in the Pathway to College in China: When Do Students from Poor Areas Fall Behind?" The China Quarterly 229:172-94.

Mare, Robert D. 1980. "Social Background and School Continuation Decisions." Journal of the American Statistical Association 75(370):295-305.

Mare, Robert D. 1981. "Change and Stability in Educational Stratification." American Sociological Review 46(1):72-87.

Mood, Carina. 2010. "Logistic Regression: Why We Cannot Do What We Think We Can Do, and What We Can Do About It." European Sociological Review 26(1):67-82.

National Bureau of Statistics of China. 2015. China Statistical Yearbook 2015. Beijing: China Statistics Press.

Nee, Victor. 1989. "A Theory of Market Transition: From Redistribution to Markets in State Socialism." American Sociological Review 54(5):663-81.

Park, Albert, Xinzheng Shi, Chang tai Hsieh, and Xuehui An. 2015. "Magnet High Schools and Academic Performance in China: A Regression Discontinuity Design." Journal of Comparative Economics 43(4):825-43.

Raftery, Adrian E. and Michael Hout. 1993. "Maximally Maintained Inequality: Expansion, Reform and Opportunity in Irish Education, 1921-75." Sociology of Education 66(1):41-62.

Rosen, Stanley. 1985. “Recentralization, Decentralization, and Rationalization: Deng Xiaoping's Bifurcated Educational Policy." Modern China 11(3):301-46. 
Ross, Heidi and Suzanne Pepper. 1997. Radicalism and Education Reform in Twentieth-Century China: The Search for an Ideal Development Model. Cambridge: Cambridge University Press.

Schindler, Steffen and Markus Lörz. 2012. "Mechanisms of Social Inequality Development: Primary and Secondary Effects in the Transition to Tertiary Education between 1976 and 2005." European Sociological Review 28(5):647-60.

Shavit, Yossi and Hans-Peter Blossfeld, eds. 1993. Persistent Inequality: Changing Educational Attainmentin Thirteen Countries. Boulder: Westview Press.

Shavit, Yossi, Meir Yaish, and Eyal Bar-Haim. 2007. "The Persistence of Persistent Inequality." Pp. 3757 in From Origin to Destination: Trends and Mechanisms in Social Stratification Research, edited by S. Scherer, R. Pollak, G. Otte, and M. Gangl. Frankfurt: Campus Verlag.

Szelenyi, Ivan and Eric Kostello. 1996. "The Market Transition Debate: Toward a Synthesis?" American Journal of Sociology 101(4):1082-96.

Tam, Tony and Jin Jiang. 2015. “Divergent Urban-Rural Trends in College Attendance: State Policy Bias and Structural Exclusion in China." Sociology of Education 88(2):160-80.

Torche, Florencia. 2005. "Privatization Reform and Inequality of Educational Opportunity: The Case of Chile." Sociology of Education 78(4):316-43.

Torche, Florencia. 2010. "Economic Crisis and Inequality of Educational Opportunity in Latin America." Sociology of Education 83(2):85-110.

Treiman, Donald J. 1970. "Industrialization and Social Stratification." Sociological Inquiry 40(2):20734.

Treiman, Donald J. 2013. "Trends in Educational Attainment in China." Chinese Sociological Review 45(3):3-25.

Tsang, Mun C. 2000. "Education and National Development in China since 1949: Oscillating Policies and Enduring Dilemmas." China Review 579-618.

Wang, Xiaobing, Chengfang Liu, Linxiu Zhang, Renfu Luo, Thomas Glauben, Yaojiang Shi, Scott Rozelle, and Brian Sharbono. 2011. "College Education and the Poor in China: Documenting the Hurdles to Educational Attainment and College Matriculation." Asia Pacific Education Review 12(4):53346.

Van de Werfhorst, Herman G. and Jonathan J. B. Mijs. 2010. "Achievement Inequality and the Institutional Structure of Educational Systems: A Comparative Perspective." Annual Review of Sociology 36(1):407-28.

Whyte, Martin King and Dong Kyun Im. 2014. "Is the Social Volcano Still Dormant? Trends in Chinese Attitudes toward Inequality." Social Science Research 48:62-76.

Wu, Xiaogang. 2010. "Economic Transition, School Expansion and Educational Inequality in China, 1990 - 2000." Research in Social Stratification and Mobility 28(1):91-108. 
Wu, Xiaogang. 2012. "The Household Registration System and Rural-Urban Educational Inequality in Contemporary China." Chinese Sociological Review 44(2):31-51.

Wu, Xiaogang. 2017. "Higher Education, Elite Formation and Social Stratification in Contemporary China: Preliminary Findings from the Beijing College Students Panel Survey." Chinese Journal of Sociology 3(1):3-31.

Wu, Xiaogang and Donald J. Treiman. 2004. "The Household Registration System and Social Stratification in China: 1955-1996." Demography 41(2):363-84.

Wu, Xiaogang and Donald J. Treiman. 2007. "Inequality and Equality under Chinese Socialism: The Hukou System and Intergenerational Occupational Mobility." American Journal of Sociology 113(2):415-45.

Wu, Xiaogang and Zhuoni Zhang. 2010. "Changes in Educational Inequality in China, 1990-2005: Evidence from the Population Census Data." Pp. 123-52 in Globalization, Changing Demographics, and Educational Challenges in East Asia, edited by E. Hannum, H. Park, and Y. G. Butler. Emerald Group Publishing Limited.

Xie, Yu and Jingwei Hu. 2014. "An Introduction to the China Family Panel Studies (CFPS)." Chinese Sociological Review 47(1):3-29.

Xie, Yu and Xiang Zhou. 2014. "Income Inequality in Today's China." Proceedings of the National Academy of Sciences 111(19):6928-33.

Yang, Wenhui and Ling Chen. 2016. "Political Capital and Intergenerational Mobility: Evidence from Elite College Admissions in China." Chinese Journal of Sociology 2(2):194-213.

Ye, Hua. 2015. "Key-Point Schools and Entry into Tertiary Education in China." Chinese Sociological Review 47(2):128-53.

Yeung, Wei-jun Jean. 2013. "Higher Education Expansion and Social Stratification in China." Chinese Sociological Review 45(4):54-80.

Yu, Nannan, Bo Yu, Martin de Jong, and Servaas Storm. 2015. "Does Inequality in Educational Attainment Matter for China's Economic Growth?" International Journal of Educational Development 41:164-73.

Zhou, Xiang. 2014. "Increasing Returns to Education, Changing Labor Force Structure, and the Rise of Earnings Inequality in Urban China, 1996-2010." Social Forces 93(2):429-55.

Zhou, Xueguang, Phyllis Moen, and Nancy Brandon Tuma. 1998. "Educational Stratification in Urban China: 1949-94." Sociology of Education 71(3):199-222. 


\section{TABLES}

Table 1. Descriptive statistics for the analytical sample, by birth cohort

\begin{tabular}{llllll}
\hline & Cohort 1 & Cohort 2 & Cohort 3 & Cohort 4 & Cohort 5 \\
& $1960-64$ & $1965-69$ & $1970-74$ & $1975-79$ & $1980-87$ \\
\hline Transition rates & & & & & \\
$\quad$ Completing primary (T1) & 76.4 & 75.4 & 79.4 & 86.4 & 92.4 \\
JHS I primary (T2) & 77.2 & 63.5 & 66.0 & 73.1 & 81.6 \\
SHS | JHS (T3) & 42.1 & 34.2 & 40.6 & 47.0 & 55.6 \\
College | SHS (T4) & 18.1 & 32.6 & 44.1 & 51.9 & 57.0 \\
Educational attainment (\%) & & & & & \\
Less than primary & 23.6 & 24.6 & 20.6 & 13.6 & 7.6 \\
$\quad$ Primary school & 17.4 & 27.5 & 27.0 & 23.3 & 17.0 \\
Junior High School & 34.2 & 31.5 & 31.1 & 33.5 & 33.5 \\
$\quad$ Senior High School & 20.3 & 11.0 & 11.9 & 14.2 & 18.0 \\
College & 4.5 & 5.3 & 9.4 & 15.4 & 23.9 \\
Parent education (\%) & & & & & \\
Less than primary & 54.8 & 43.7 & 32.3 & 24.4 & 15.7 \\
$\quad$ Primary school & 29.6 & 32.8 & 36.8 & 36.6 & 24.9 \\
Junior High School & 9.5 & 14.2 & 19.0 & 22.8 & 32.1 \\
Senior High School & 4.3 & 6.9 & 9.3 & 14.1 & 23.2 \\
College & 1.8 & 2.4 & 2.6 & 2.1 & 4.1 \\
Parent(s) party member (\%) & 21.4 & 20.1 & 19.3 & 21.2 & 17.2 \\
Male (\%) & 49.2 & 48.7 & 49.6 & 48.7 & 48.2 \\
Urban hukou at age 12 (\%) & 17.7 & 13.4 & 17.0 & 17.2 & 22.9 \\
\hline Observations & 3116 & 3638 & 3386 & 2443 & 3839 \\
\hline
\end{tabular}

Note: weighted percentages, unweighted $N$ 
Table 2. Results from the sequential logit models: odds ratios [in brackets], by birth cohort

\begin{tabular}{|c|c|c|c|c|c|}
\hline & $1960-64$ & $1965-69$ & $1970-74$ & $1975-79$ & $1980-87$ \\
\hline \multicolumn{6}{|l|}{ T1 (completing primary) } \\
\hline \multicolumn{6}{|c|}{ Parent education (ref: primary) } \\
\hline Less than primary & $0.487^{* * *}$ & $0.361^{* * *}$ & $0.383^{* * *}$ & $0.258^{* * *}$ & $0.251^{* * *}$ \\
\hline Junior High & 1.212 & 1.027 & $1.736^{* * *}$ & $2.050^{* * *}$ & $3.141^{* * *}$ \\
\hline Senior High or College & $2.054^{*}$ & 1.294 & $1.694^{* *}$ & $2.794^{* * *}$ & $4.952^{* * *}$ \\
\hline Party member & 1.190 & $1.555^{* * *}$ & $1.310^{*}$ & 1.257 & 1.419 \\
\hline Male & $4.060^{* * *}$ & $2.127^{* * *}$ & $2.245^{* * *}$ & $2.134^{* * *}$ & $1.428^{* *}$ \\
\hline Urban hukou & $10.000^{* * *}$ & $9.320^{* * *}$ & $7.225^{* * *}$ & $28.94^{* * *}$ & $3.282^{* * *}$ \\
\hline \multirow[t]{2}{*}{ Observations } & 3163 & 3681 & 3458 & 2528 & 4189 \\
\hline & $1960-64$ & $1965-69$ & $1970-74$ & $1975-79$ & $1980-87$ \\
\hline \multicolumn{6}{|l|}{ T2 (JHS I Primary) } \\
\hline \multicolumn{6}{|c|}{ Parent education (ref: primary) } \\
\hline Less than primary & $0.696^{* *}$ & $0.561^{* * *}$ & $0.571^{* * *}$ & $0.509^{* * *}$ & $0.653^{* * *}$ \\
\hline Junior High & 1.300 & $1.395^{*}$ & $1.479^{* *}$ & 1.226 & $1.535^{* * *}$ \\
\hline Senior High & 1.117 & 1.213 & $1.856^{* * *}$ & $1.539^{*}$ & $2.280^{* * *}$ \\
\hline College & $5.080^{*}$ & $3.997^{* *}$ & $3.063^{*}$ & 5.545 & $4.769^{* *}$ \\
\hline Party member & $1.558^{* *}$ & $1.380^{* *}$ & 1.197 & $1.556^{* *}$ & $1.450^{*}$ \\
\hline Male & $1.642^{* * *}$ & $1.256^{* *}$ & $1.537^{* * *}$ & $1.268^{*}$ & 1.134 \\
\hline Urban hukou & $6.492^{* * *}$ & $12.86^{* * *}$ & $6.902^{* * *}$ & $6.481^{* * *}$ & $6.255^{* * *}$ \\
\hline \multirow[t]{2}{*}{ Observations } & 2367 & 2608 & 2552 & 2090 & 3821 \\
\hline & $1960-64$ & $1965-69$ & $1970-74$ & $1975-79$ & $1980-87$ \\
\hline \multicolumn{6}{|l|}{ T3 (SHS | JHS) } \\
\hline \multicolumn{6}{|c|}{ Parent education (ref: primary) } \\
\hline Less than primary & $0.723^{* *}$ & $0.601^{* *}$ & $0.552^{* * *}$ & 0.940 & $0.719^{*}$ \\
\hline Junior High & 1.051 & $1.690^{* *}$ & 1.306 & $1.556^{* *}$ & $1.432^{* *}$ \\
\hline Senior High & 1.237 & $1.714^{* *}$ & $1.945^{* * *}$ & $2.265^{* * *}$ & $2.222^{* * *}$ \\
\hline College & $2.297^{* *}$ & $2.654^{* * *}$ & $4.028^{* * *}$ & $4.251^{* * *}$ & $6.389^{* * *}$ \\
\hline Party member & $1.334^{*}$ & $1.874^{* * *}$ & $1.436^{* *}$ & 1.035 & $1.531^{* * *}$ \\
\hline Male & 1.143 & $1.432^{* *}$ & $1.252^{*}$ & 1.099 & 0.977 \\
\hline Urban hukou & $2.695^{* * *}$ & $4.439^{* * *}$ & $3.562^{* * *}$ & $3.964^{* * *}$ & $5.670^{* * *}$ \\
\hline \multirow[t]{2}{*}{ Observations } & 1795 & 1564 & 1640 & 1504 & 2985 \\
\hline & $1960-64$ & $1965-69$ & $1970-74$ & $1975-79$ & $1980-87$ \\
\hline \multicolumn{6}{|l|}{ T4 (College | SHS) } \\
\hline \multicolumn{6}{|c|}{ Parent education (ref: primary) } \\
\hline Less than primary & 0.827 & $0.373^{* *}$ & 1.277 & 0.867 & 1.047 \\
\hline Junior High & 1.122 & 0.988 & 1.319 & 1.232 & 1.179 \\
\hline Senior High & $5.171^{* * *}$ & 1.709 & $2.093^{* *}$ & $2.408^{* * *}$ & $1.715^{* * *}$ \\
\hline College & $2.631^{*}$ & 1.936 & $4.023^{* * *}$ & $3.895^{* *}$ & $3.550^{* * *}$ \\
\hline Party member & 1.169 & 1.488 & 1.072 & 0.815 & $1.341^{*}$ \\
\hline Male & 1.353 & 1.379 & 1.137 & 0.911 & 0.929 \\
\hline Urban hukou & 1.152 & 1.100 & 0.796 & $1.516^{*}$ & $1.942^{* * *}$ \\
\hline Observations & 766 & 506 & 625 & 685 & 1589 \\
\hline
\end{tabular}

Note: ${ }^{*} p<0.05,{ }^{* *} p<0.01,{ }^{* * *} p<0.001$ 


\section{FIGURES}

Figure 1: The Chinese education system

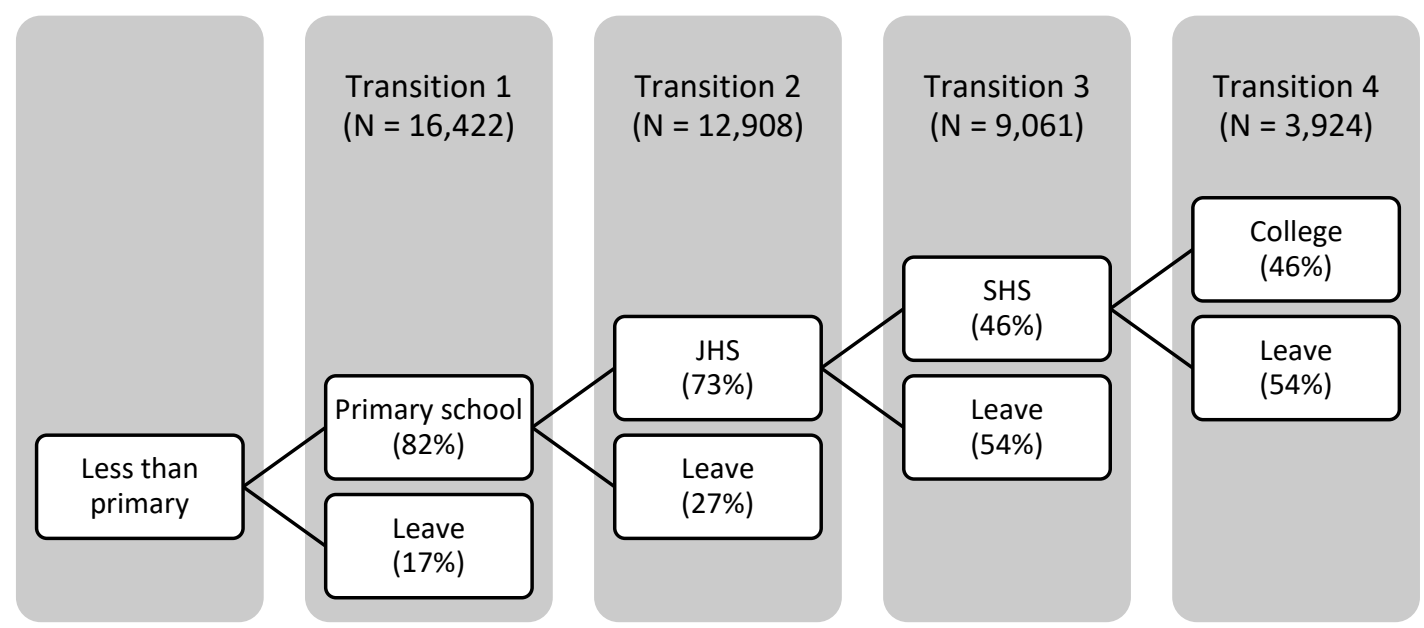

Note: $N$ (unweighted) and percentages (weighted) refer to the CFPS sample included in this study (individuals born between 1960 and 1987) 
Figure 2: Educational attainment of respondents, by birth cohort and hukou status at age 12

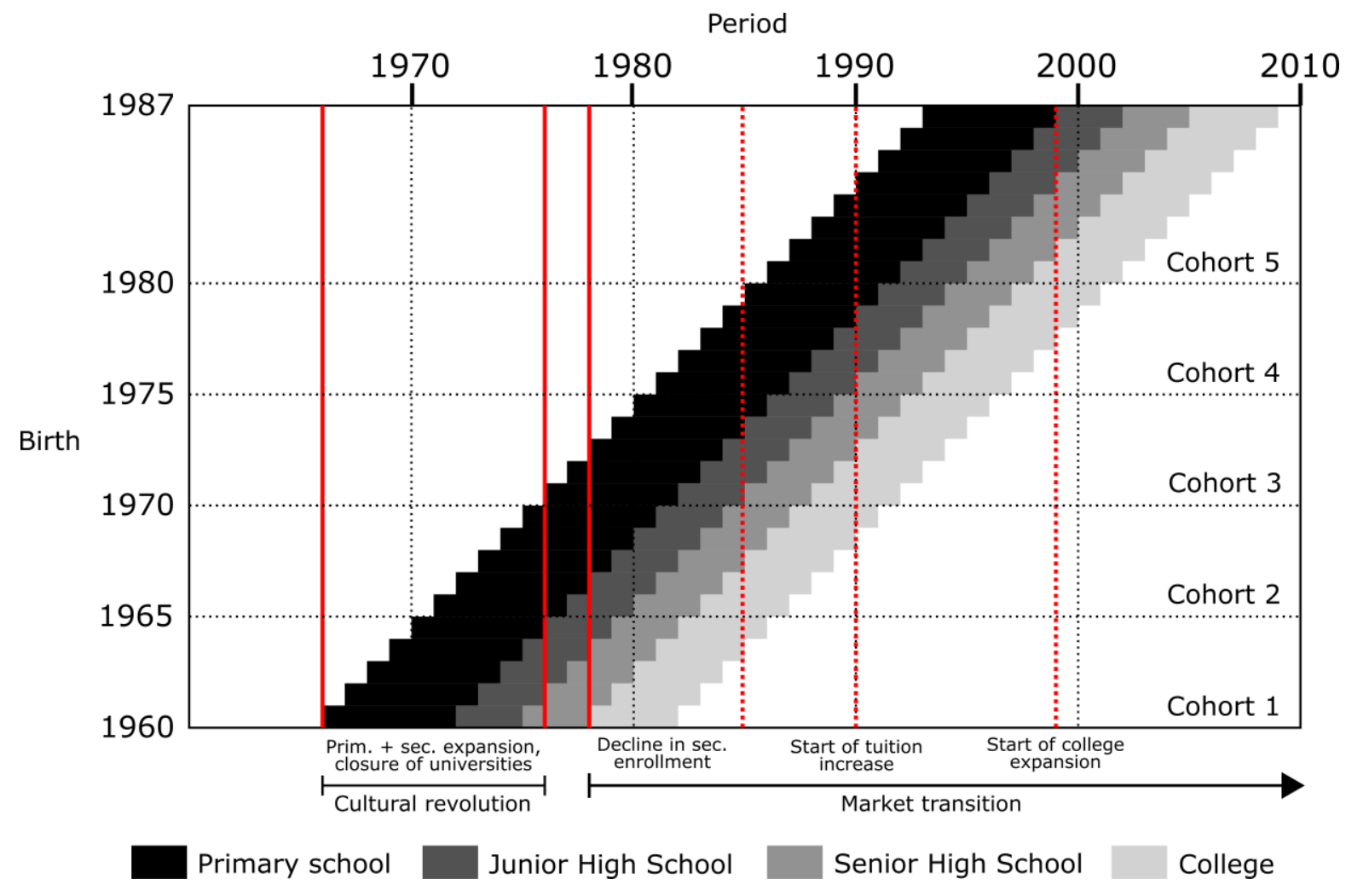

Note: the graph should be read from left to right: birth cohorts pass though historical periods. 
Figure 3: Average conditional transition probabilities, by birth cohort and parents' education
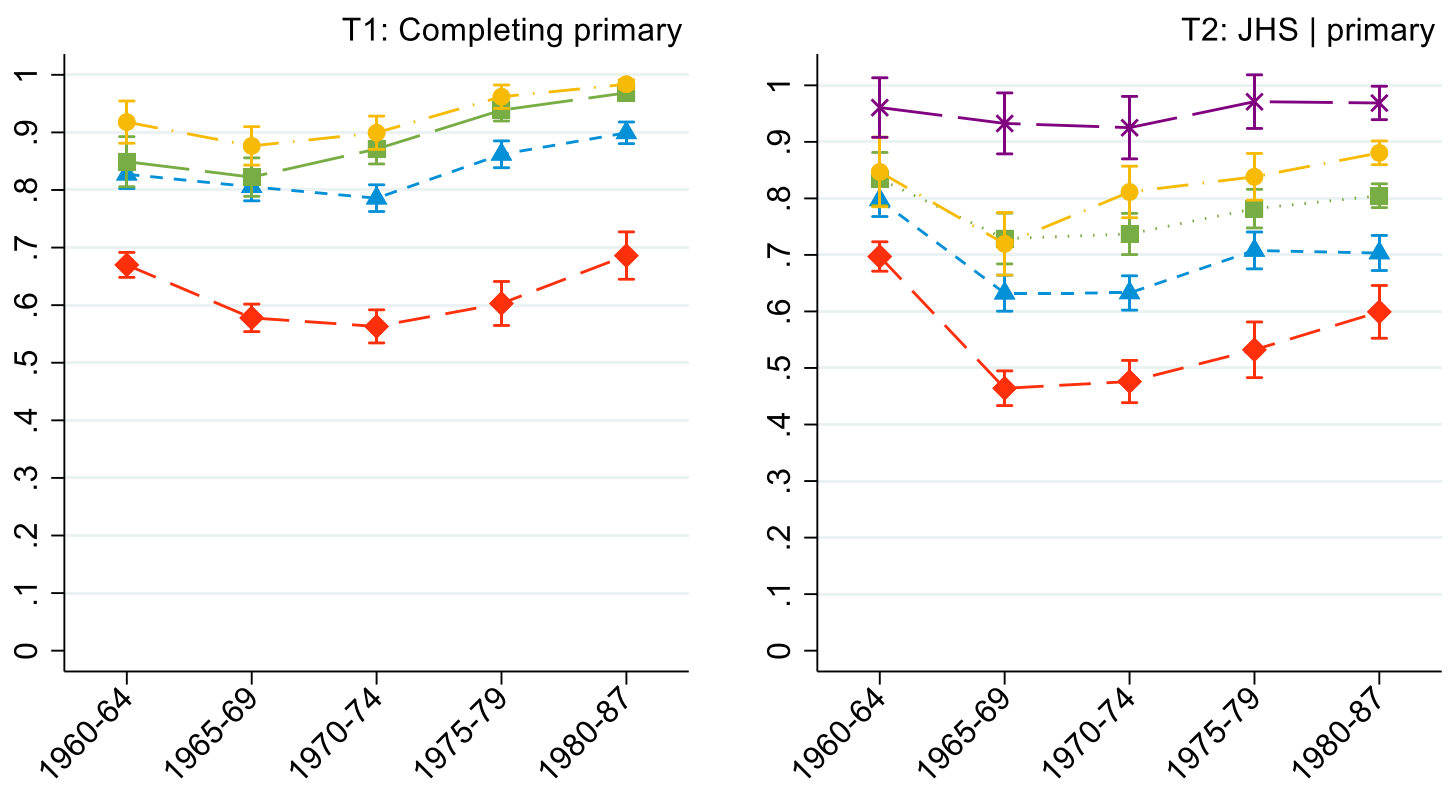

T3: SHS | JHS

T4: College | SHS
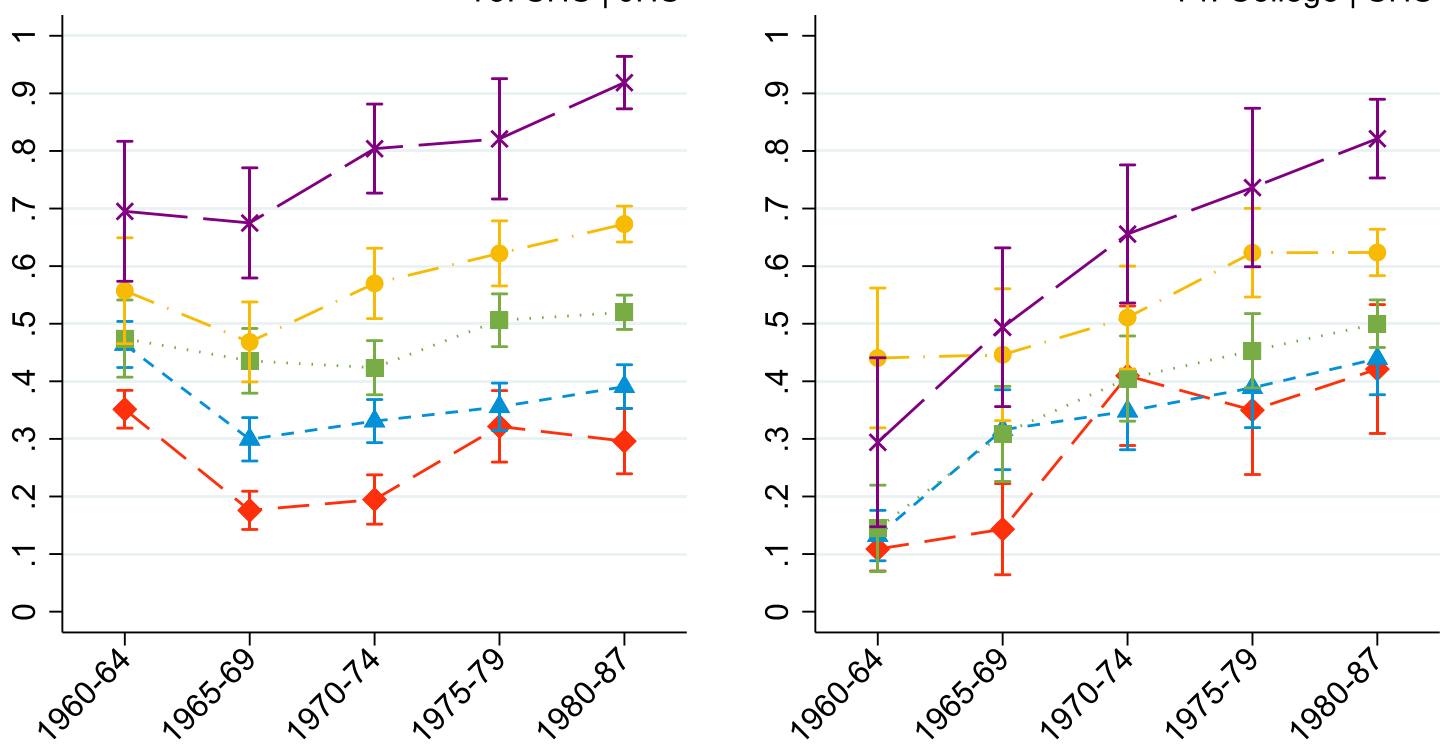

Parents education:

- Less than primary $-\perp$ - Primary $\cdots$ JHS $-\mathrm{O}$ - SHS $\rightarrow$ College

Note: Average predicted transition probabilities from weighted sequential logit models including parental education, parents' Communist party membership, hukou status and gender as predictors. Please note that for $T 1$ the parental education categories 'SHS' and 'College' have been combined, in order to prevent perfect prediction. 
Figure 4: Average conditional transition probabilities: by birth cohort and parents' party membership
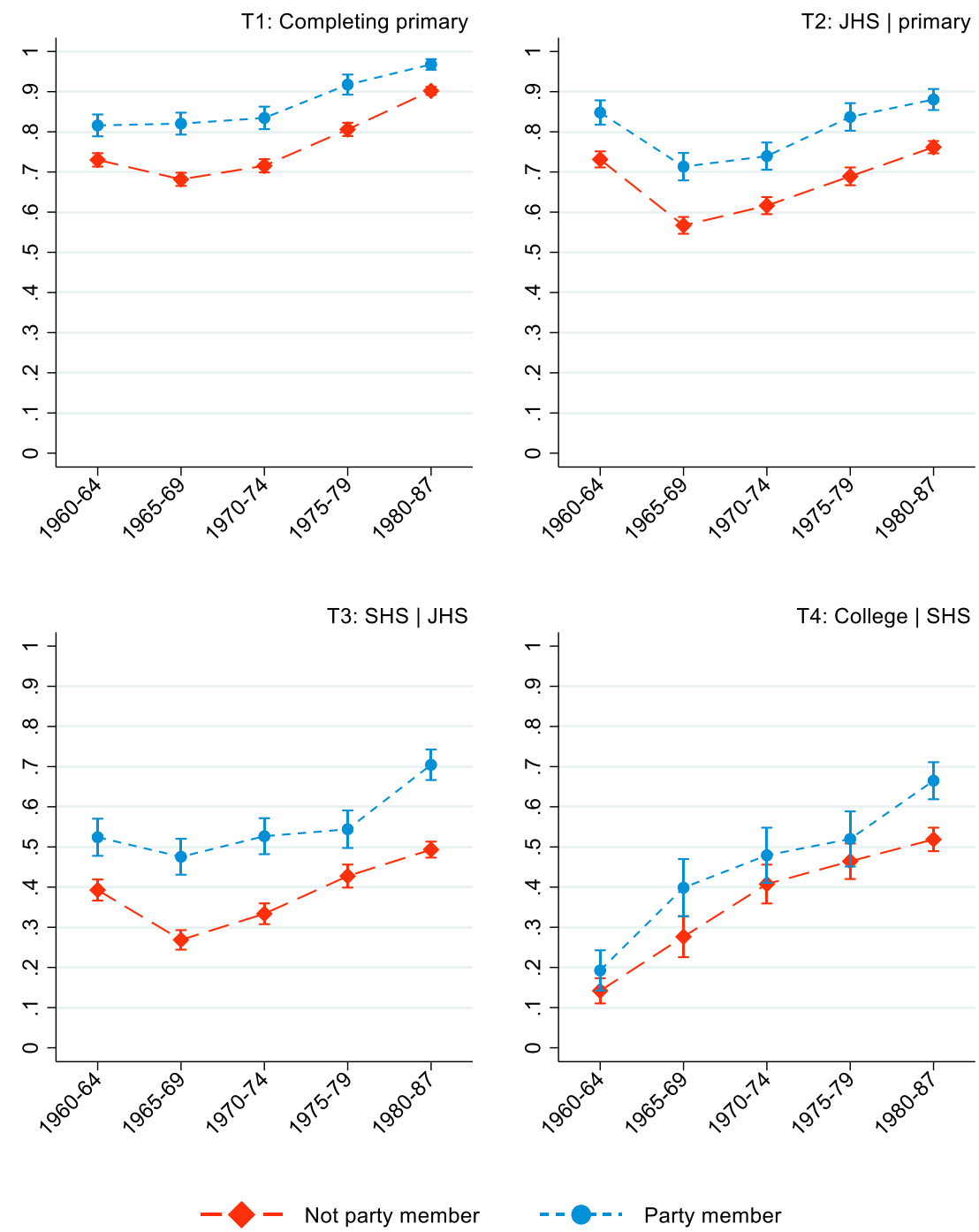

Note: Average predicted transition probabilities from weighted sequential logit models including parental education, parents' Communist party membership, hukou status and gender as predictors. 
Figure 5: Average conditional transition probabilities: by birth cohort and household registration at age 12
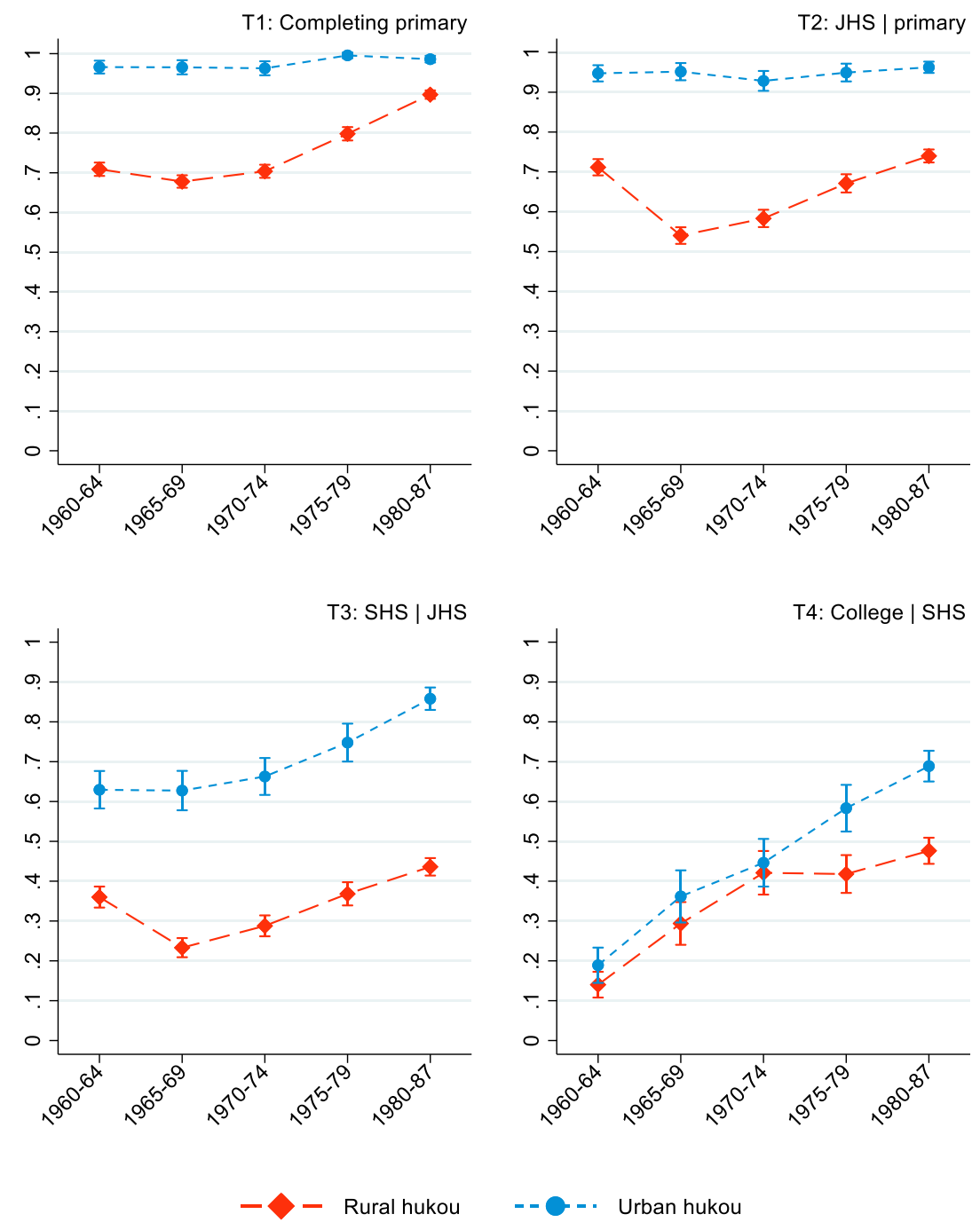

Note: Average predicted transition probabilities from weighted sequential logit models including parental education, parents' Communist party membership, hukou status and gender as predictors. 
Figure 6: Predicted educational attainment, by birth cohort and family background

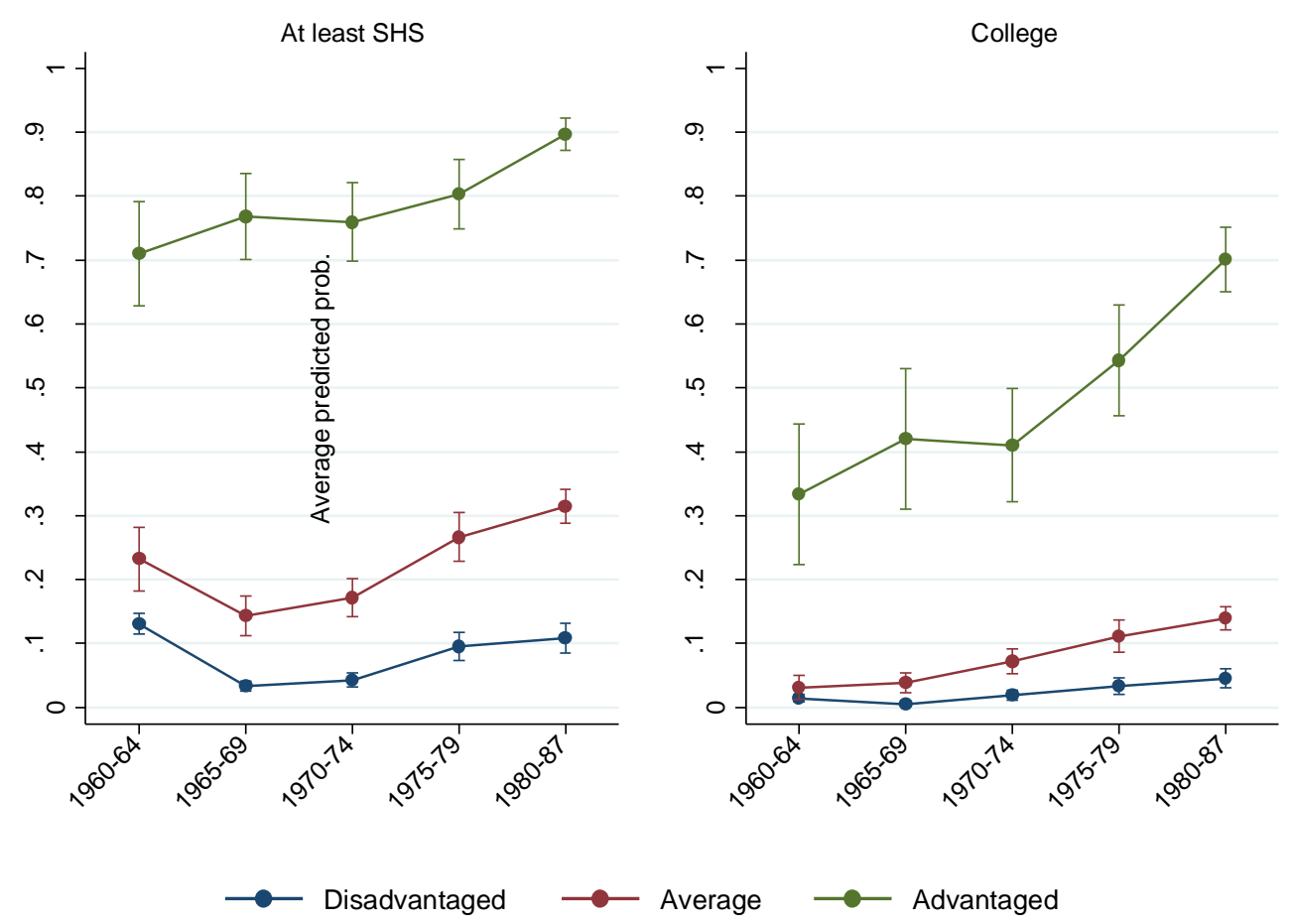

Note: Average predicted probabilities for three different combinations of family background variables (see text), controlling for hukou and gender. These probabilities are derived from logistic regression models, by cohort, using the full analytical sample (see Annex Table 1 for the full results). 